\title{
Safe and sustainable waste management of self care products
}

\section{A safe and sustainable waste management system for self care products requires education and multisectoral approaches say Ash Pachauri and colleagues}

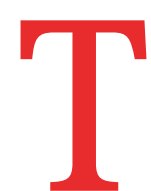
he global growth rate of self care medical devices is estimated to rise from $\$ 10.5 \mathrm{bn}$ ( $€ 8 \mathrm{bn}, € 9.2 \mathrm{bn}$ ) in 2013 to $\$ 16.8$ bn in $2019-$ a compound annual growth rate of $7.0 \%{ }^{1}$ This increase directly correlates with the level of disposables entering the waste stream. Additionally, over half of the world's population is now at risk from occupational, environmental, or public health threats due to improper management of healthcare waste. ${ }^{2}$ Waste management of products used for self care is largely unregulated and evidence is limited.

The World Health Organization defines self care as the "ability of individuals, families, and communities to promote health, prevent disease, maintain health, and cope with illness and disability with or without the support of a healthcare provider." ${ }^{3}$ Self care products include a variety of sexual and reproductive health commodities such as condoms, tampons, sanitary pads, and self administered injectables. An analysis of these commodities shows the magnitude of waste management challenges facing individuals, communities, and governments worldwide.

\section{KEY MESSAGES}

- Self care will continue to grow, especially as it is seen as key to reaching universal health coverage by 2030 , as part of the sustainable development goals

- Research is needed to clearly understand the effect of unregulated waste from self care products on human health and the environment

- National policies and regulatory frameworks are urgently required to enable the adoption of safe waste management techniques and the development of efficient production methods

- Safe and sustainable self care product waste management necessitates the development of cross sectoral partnerships and action by all players in the system

\section{Magnitude of the problem}

The magnitude of waste arising from self care products depends on the amount of user generated and segregated waste and the quality of treatment and disposal by the wider waste management system. In the case of condoms, most for men and some for women are made of rubber latex, which is biodegradable, except in water. ${ }^{4}$ Some condoms contain polyurethane, which is non-biodegradable. ${ }^{4}$ Their primary and secondary packaging also adds to the waste burden. An estimated five billion packets of condoms are sold annually, ${ }^{56}$ which contribute to beach litter, blockage of sewage systems, and breeding of vectors. ${ }^{7}$ In 2013, during the New Jersey beach clean-up, volunteers removed 744 condoms or rubber bands, 511 gloves, and 3102 tampon applicators. $^{8}$

Condoms are a critical, cost effective method of contraception when used correctly. Their continued availability remains important for reducing mortality and morbidity, but social marketing interventions hardly mention proper disposal, although they have the potential to do so.

Women who have access to menstrual hygiene products might use up to 10000 12000 during their lifetime. ${ }^{9}$ Sanitary pads consist of up to $90 \%$ plastic and take around 500-800 years to biodegrade. ${ }^{9}$ One sanitary pad may contain as much plastic as four supermarket bags. ${ }^{10}$ This causes problems for waste management worldwide. In 2016, the British Marine Conservation Society found 20 sanitary items per 100 metres of shoreline. ${ }^{11}$ The Menstrual Health Alliance estimates that 9000 tons of sanitary waste are generated annually in India. ${ }^{12}$ Typically, this is disposed of with household waste. Disposal is often improperly managed by local authorities, with sanitary products ending up in the oceans and waterways. ${ }^{12}$

For many women and girls, disposable sanitary pads and tampons remain inaccessible or unaffordable. ${ }^{13}$ Menstrual Hygiene Day, initiated by the German based non-governmental organisation WASH United, builds awareness, particularly through social media, about the fundamental role of good menstrual hygiene in enabling women and girls to reach their full potential. ${ }^{13}$ The initiative catalyses a global movement to promote safe disposal of these items through reduction, segregation, and treatment. ${ }^{14}$

The transmission rates of bloodborne viruses from patient to healthcare worker are up to $30 \%$ for hepatitis B (HBV), 1-3\% for hepatitis C (HCV), and $0.3 \%$ for HIV due to improperly disposed sharps. These numbers may not result from inoculation of fresh blood as the viruses survive outside the body for varying lengths of time, from four days to three weeks. ${ }^{15} 16$ In 2010, unsafe injections from re-use were responsible for 33800 new HIV, 1.7 million HBV, and $315000 \mathrm{HCV}$ infections globally. ${ }^{17}$ A study of 141 rubbish collectors in Karachi reported the prevalence of HBV as $18.8 \%$, HCV $8.5 \%$, and HIV $0.85 \%$, ${ }^{18}$ with baseline prevalence rates of $2.5 \%$, $5 \%$, and $0.1 \%$, respectively, among adult populations in Pakistan. ${ }^{1920}$ In the same study it was found that $54 \%$ of them had had more them one needlestick injury. Self injection of contraceptives is expected to be increasingly available. This requires cross-sectoral partnerships and guidance for better manufacturing, distribution, and disposal of sharps.

\section{Implications of unregulated waste from self care products}

Unregulated, and even regulated, improper waste disposal is not unique to self care products. Inappropriate waste burial may cause leaching of toxins and microorganisms into waterways, ${ }^{21}$ incineration increases greenhouse gas emissions, and dioxins and furans have been associated with a wide range of human health problems. ${ }^{21}$ Plastics, commonly used for packaging, break down into microscopic fragments (microplastics), ${ }^{22}$ which are being ingested by people worldwide. However, little is known about their effect on human health and ecology. ${ }^{22}$

Access to good quality products when needed forms part of the right to healthcare. As we reduce dependence on hospitals 
and enhance our reliance on community based systems, and self management, waste disposal of self care products will rise substantially. This adds a sense of urgency, as the need for such products is sometimes coupled with unregulated waste management. Economic and social inequities exacerbate the problem, with the poorest, most vulnerable populations in low and middle income countries at highest risk of adverse health and environmental effects. Evidence suggests that although per capita waste generation is highest in the developed world, these countries have better waste management practices that mitigate potential adverse health effects. ${ }^{23}$

Global practices of dealing with self care waste Many countries have schemes for safe disposal of certain self care products outside healthcare facilities. These include dropoff container collection sites, residential special waste pickup services, mail back programmes, unused medicine take back and disposal options, syringe exchange programmes, and home needle destruction devices. ${ }^{24}$ However, such opportunities are not universal and there is resistance to the collection of home medical waste in municipalities because its classification (as home or industrial waste), and hence management, is unclear. ${ }^{25}$

For large quantities of condoms, shredding or compacting is a recommended method of disposal, ${ }^{4}$ eliminating the risk of scavenging and condom reuse. However, condoms are difficult to shred, ${ }^{4}$ and anaerobic degradation (due to compacting or burial) of plastic and rubber produces carbon dioxide and methane, ${ }^{4}$ both of which are major greenhouse gases. Some condom manufacturers are obtaining latex directly from rubber trees, ${ }^{6}$ packaging in recycled paper boxes, and printing directions with vegetable ink. ${ }^{6}$ Such products are easily available online and cost between $\$ 1$ and $\$ 1.5$ a piece. ${ }^{26}$ Others have begun producing menstrual products using sustainable materials (eg, wood pulp replacing plastic fillers in sanitary pads) and reusable products (eg, menstrual cups), ${ }^{27}$ thus dealing with equity and environmental considerations. Some of these are $100 \%$ biodegradable and $43 \%$ cheaper than the average retail price. ${ }^{28}$

\section{Life cycle analysis and associated accountability}

Disposal of a product is one of many costs incurred during its life cycle. Accountability can be ascertained by examining each stakeholder's role in key stages of a product's manufacture, procurement, distribution, and use. For instance, United Nations Population Fund's (UNPFA) replicable green procurement strategy involved collaboration with donors, governments, beneficiaries, and suppliers. It clearly communicated details of the plan, thus leading to savings of 7.8 metric tons of $\mathrm{CO}_{2}, 11.8$ million $\mathrm{kg}$ of solid waste, and $587598 \mathrm{~m}^{3}$ of water in $2010 .^{29}$ Similarly, a study evaluating the effect of syringe acquisition on syringe disposal indicated that HIV positive injection drug users who obtain syringes from a safe source are more likely to dispose of them safely. ${ }^{30}$

Consumers are beginning to play an active part in making decisions about their health. ${ }^{31}$ It is therefore necessary to develop a system that provides them with critical information, and sets a strong precedent for greener supply chains, reducing both the amount of waste and the cost of disposal. Some companies, however, seem to potentially mislead consumers by replacing restricted materials with little known and legally permissible materials that may have similar physiological effects (eg, replacement of bisphenol A with bisphenol $\mathrm{S}$ or bisphenol $\mathrm{F}^{32}$ ). Users and policy makers responsible for regulation of chemical usage require access to this information and the ability to evaluate it.

\section{Facilitating holistic self care waste management through cross-sectoral partnerships}

A robust self care system will depend on cross sectoral partnerships which create healthy communities, towns, and cities. ${ }^{33}$ UNFPA's green procurement strategy is an example of collaborative action that included donors, governments, suppliers, and beneficiaries. ${ }^{29}$ While building on existing systems, care must be taken to consider the broader effect of establishing more formal waste management. Thus, for example, the livelihoods and occupational safety of waste handlers in the informal sectors must be considered. ${ }^{34}$

Based on analysis of reports from the fields of healthcare waste management, ${ }^{213536}$ sustainability and the environment, ${ }^{22}$ and waste management from home care and non-medical settings, ${ }^{37-39}$ actions in specific sectors can be developed that lead to better waste management of self care products:

- Governments-The importance of integrated solid waste management by city governments based on the 3 Rs-reduce, reuse, and recycle-is well recognised as the basis of sustain- able development. ${ }^{40}$ National governments could also improve their waste management. Targeted budgets could be developed to build and maintain cleaner technologies, ${ }^{41}$ and policies that include environmental or health externalities in product pricing.

- Non-governmental organisationsWhile advocating promotion and use of self care, non-governmental organisations could implement home and community based programmes for waste management. Interventions to change behaviour, which have shown great potential in individual and community waste management practices, may also be introduced. These could educate communities and improve consumer knowledge, attitudes, and practices towards safe and sustainable waste management of self care products. $^{35}$

- Private sector-The concept of a stronger, more circular economy offers the private sector an opportunity to promote the use of safe and efficient materials, reduce waste, and prioritise products with low carbon footprints. This would reduce energy costs, while creating environmental and health benefits. ${ }^{42}$ The private sector could develop solutions to reduce the volume and toxicity of waste by using regulated materials and alternative, safe packaging. It may also include the social, environmental, and financial analyses used to evaluate performance and create greater value while exploring possibilities of waste collection that is not carried out by the municipality.

- Consumers-Education on reducing the volume of waste generated, on waste segregation, recycling practices, and on attitudes towards waste, has been shown to have a positive effect. ${ }^{35}$ Thus, large scale public awareness could create a change in consumer attitudes.

- Donors and development partnersDonors can influence development ${ }^{43}$ and could set priorities, affect policy, and make financing decisions to ensure sustainable waste management systems for self care products. They may also introduce and monitor such systems and support research needed to identify means for cleaning the environment and improving public health. By collaborating with the private sector and governments, donors might also be able to ensure sustain- 
able waste management as health systems are expanded in developing economies.

- Researchers-The importance of research in protecting our planet and promoting public health cannot be denied. ${ }^{44}$ Recognising the urgency of dealing with self care product waste, researchers should focus on understanding its effect on the environment. They should consider operational solutions, including production and packaging, inventory management, procurement strategies, disposal techniques, and routeing and transportation. Interdisciplinary and transdisciplinary research is required.

\section{Conclusions}

Self care will form an important part of healthcare systems as governments strive to achieve universal health coverage by 2030, as part of the sustainable development goals. However, waste management of self care products cannot be neglected, particularly for poor and vulnerable populations. While waste generated by regulated hospitals continues to cause alarm, the problem of uncontrolled self care products waste appears to be quietly growing. This is an urgent call to understand its sustainability implications and facilitate the design of policies and development of programmes to promote sustainable waste management. This is the responsibility of all, and not only of the user. Countries should be supported to develop and adopt routes to sustainable self care waste management that include increasing access and developing methods to protect human and environmental health.

We are grateful for feedback from a group of committed people who participated in the WHO Wilton Park expert meeting "Reimagining Global Health: Self-Initiated Interventions and Implications for Healthcare," 10-12 September 2018. Special thanks to Saroj Pachauri and Shonali Pachauri for their invaluable input.

Competing interests: We have read and understood BMJ policy on declaration of interests and have no relevant interests to declare.

Contributors and sources: AP is a public health researcher with expertise in social mobilisation and behaviour change communication. PS is an environmentalist whose work focuses on environmental health and behavioural science research. BCA carries out research into the effects of microplastics and chemicals in food chains, as well as chemicals in plastic packaging. NPMS is a researcher with expertise in biological oceanography, marine biochemistry, environmental deterioration, and climate change. MN is a scientist with expertise in sexual and reproductive health and rights, and is leading the WHO normative guidance development on self care. AP and MN conceived the idea for the article. AP and PS wrote the first draft. AP, PS, BCA,
NPMS, MN revised the paper. AP is the guarantor. The contents are the responsibility of the authors and do not necessarily reflect the views of WHO.

Provenance and peer review: Commissioned; externally peer reviewed.

This article is part of a series proposed by the UNDP/ UNFPA/Unicef/WHO/World Bank Special Programme for Human Reproduction (HRP) and commissioned by The $B M J$. The $B M$ J retained full editorial control over external peer review, editing, and publication of these articles. Open access fees are funded by HRP.

Ash Pachauri, director ${ }^{1}$

Prerna Shah, honorary researcher and environmentalist ${ }^{2}$

Bethanie C Almroth, senior lecturer ${ }^{3}$

Norma P M Sevilla, professor ${ }^{4}$

Manjulaa Narasimhan, scientist $t^{5}$

${ }^{1}$ Center for Human Progress, Ashburn, Virginia 20148, USA

${ }^{2}$ Protect our Planet (POP) Movement, G-1, Jangpura Extension, New Delhi, India

${ }^{3}$ Department of Biological and Environmental Sciences, University of Gothenburg, Gothenburg, Sweden

${ }^{4}$ Interdisciplinary Center for Research and Studies on Environment and Development, National Polytechnic Institute, Mexico City, Mexico

${ }^{5}$ World Health Organization, including UNDP/UNFPA/ Unicef/WHO/World Bank Special Programme (HRP), Geneva, Switzerland

Correspondence to: A Pachauri

ash.pachauri@gmail.com

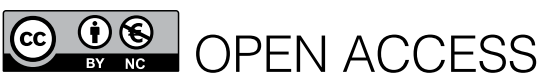

This is an Open Access article distributed under the terms of the Creative Commons Attribution IGO License (https://creativecommons.org/licenses/ by-nc/3.0/igo/), which permits use, distribution, and reproduction for non-commercial purposes in any medium, provided the original work is properly cited.

\section{Check for updates}

1 Transparency Market Research. Self-care medical devices market- global industry analysis, size, share and forecast 2013-2019. https://www. transparencymarketresearch.com/self-care-medicaldevices.html

2 Harhay MO, Halpern SD, Harhay JS, Olliaro PL. Health care waste management: a neglected and growing public health problem worldwide. Trop Med Int Health 2009;14:1414-7. doi:10.1111/j.13653156.2009.02386.x

3 Levin LS, Idler EL. Self-care in health. Annu Rev Public Health 1983;4:181-201. doi:10.1146/annurev. pu.04.050183.001145

4 UNFPA. Safe disposal and management of unused unwanted contraceptives. 2013. https://www.unfpa. org/resources/safe-disposal-and-managementunused-unwanted-contraceptives

5 Neporent L. 7 Facts about condoms. ABC Medical Unit, 2011. https://abcnews.go.com/Health/ condom-facts-things/story?id=12869404

6 Stacey D. Can condoms be recycled? Very Well Health, 2018. https://www.verywellhealth.com/cancondoms-be-recycled-906643

7 Ehiri JE, Birley M. Environmental impact of contraceptive use: an overview of available evidence. Environ Manage Health 2002;13:55-65. doi:10.1108/09566160210417822
8 CBS New York. Hundreds of condoms, thousands of tampon applicators found among NJ beach trash. 2013. https://newyork.cbslocal.com/2013/04/16/ hundreds-of-condoms-thousands-of-tamponapplicators-found-among-nj-beach-trash/

9 Edraki F for War on Waste. Tampons, pads, menstrual cups, period underwear: what's best for the environment? ABC News, 2017. https://www.abc.net. au/news/2017-10-27/which-period-product-is-bestfor-the-environment/9090658

10 Cooper K-L. The people fighting pollution with plasticfree periods. BBC News, 2018 https://www.bbc.com/ news/world-43879789

11 Siegle $L$. The eco guide to sanitary products. The Guardian, 2017 https://www.theguardian.com/ environment/2017/oct/29/the-eco-guide-to-perioddramas

12 Plastic based sanitary pads are not only harmful to the environment but also your body. Hindustan Times 2018. https://www.hindustantimes.com/ fitness/plastic-based-sanitary-pads-are-not-onlyharmful-to-the-environment-but-also-your-body/ story-Kk4wrl6QOyJCkP7bwEhOrl.html

13 World Health Organization. Menstrual Hygiene Day. WHO, 2018. http://www.who.int/life-course/news/ events/menstrual-hygiene-day-2018/en/

14 Muralidharan A. Management of menstrual waste: insights from India and Pakistan. Water Aid India, Menstrual Health Alliance India, 2018. http://menstrualhygieneday.org/wp-content/ uploads/2018/06/WaterAid_Arundati-Muralidharan. pdf

15 Health and Safety Executive. Risk to healthcare workers. HSE, 2019. http://www.hse.gov.uk/ biosafety/blood-borne-viruses/risk-healthcareworkers.htm

16 Humboldt State University. Bloodborne pathogens: how long do these viruses live outside the body? 2019 https://risksafety.humboldt.edu/sites/default/ files/risksafety/Bloodborne\%20FAQs.pdf

17 Pépin J, Abou Chakra CN, Pépin E, Nault V, Valiquette L. Evolution of the global burden of viral infections from unsafe medical injections, 2000-2010. PLoS One 2014;9:e99677. doi:10.1371/journal. pone.0099677

18 Rauf MUA, Saleem MD, Anwer MO, Ahmed G, Aziz S, Memon MA. HIV, hepatitis B and hepatitis $C$ in garbage scavengers of Karachi. J Pak Med Assoc 2013;63:798-802.

19 Shakeel S, Iffat W, Rehman H, et al. Assessing the level of awareness and vaccination status of hepatitis B among young female community of Pakistan. Bangladesh Journal of Medical Science 2015;14:376-83. doi:10.3329/bjms. v14i4. 25780

20 Moin A, Fatima H, Qadir TF. Tackling hepatitis C-Pakistan's road to success. Lancet 2018;391:8345. https://www.thelancet.com/journals/lancet/ article/PIIS0140-6736(18)30462-8/fulltext. doi:10.1016/S0140-6736(18)30462-8

21 World Health Organization. Health care solid waste. http://www.who.int/sustainable-development/ health-sector/health-risks/solid-waste/en/

22 The Lancet Planetary Health. Microplastics and human health-an urgent problem. Lancet Planet Health 2017;1:e254. doi:10.1016/S25425196(17)30121-3

23 Ziraba AK, Haregu TN, Mberu B. A review and framework for understanding the potential impact of poor solid waste management on health in developing countries. Arch Public Health 2016;74:55. doi:10.1186/s13690-016-0166-4

24 Majumdar A, Sahoo J, Roy G, Kamalanathan S. Improper sharp disposal practices among diabetes patients in home care settings: need for concern?Indian J Endocrinol Metab 2015;19:420-5. doi:10.4103/2230-8210.152792

25 Hanashi Y. Investigation into the proper disposal of home medical waste.Japan Medical Association Journal 2011;54:271-6. 
26 Pareek S. Low cost and eco friendly ideas which have revolutionized women's sanitary hygiene in India. The Better India, 2014.https://www.thebetterindia. com/10917/india-women-menstruation-lowcostecofriendly-sanitary-pads/

27 Barman A, Katkar PM, Asagekar SD. Natural and sustainable raw materials for sanitary napkin. Journal of Textile Science \& Engineering 2017;7:308 https://www.omicsonline.org/open-access/ natural-and-sustainable-raw-materials-for-sanitarynapkin-2165-8064-1000308.php?aid=93070.

28 Good Trade. These vegan condom brands want you to have world-changing sex. 2019. https://www. thegoodtrade.com/features/ethical-condoms

29 UNFPA. Greening the blue. Environmentally friendly male condoms. 2017. http://www.greeningtheblue.org/ news/unfpa-environmentally-friendly-male-condoms

30 Coffin PO, Latka MH, Latkin C, et al, INSPIRE Study Group. Safe syringe disposal is related to safe syringe access among HIV-positive injection drug users. AIDS Behav 2007;11:652-62. doi:10.1007/s10461-006 9171-x

31 Cordina J, Kumar R, Olson E. McKinsey on Healthcare. Enabling healthcare consumerism, 2017. https:// healthcare.mckinsey.com/enabling-healthcareconsumerism

32 Rochester JR, Bolden AL. Bisphenol S and F: a systematic review and comparison of the hormonal activity of bisphenol A substitutes. Environ Health Perspect 2015;123:643-50. doi:10.1289/ ehp.1408989
33 Crisp N. What would a sustainable health and care system look like?BMJ 2017;358:j3895. doi:10.1136/bmj.j3895

34 Wilson D, Velis C, Cheeseman CR. Role of informal sector recycling in waste management in developing countries. Habitat Int 2006;30:797-808. doi:10.1016/j.habitatint.2005.09.005

35 Nichols A, Richardson J, Pahl S, Jenkin R, Wallace G, Bennallick M. Sustainable practice and behaviour change in healthcare waste management: a review of the literature. 1st World Sustainability Forum. 2011. https://sciforum.net/manuscripts/551/original.pdf

36 Lee B-K, Ellenbecker MJ, Moure-Eraso R. Analyses of the recycling potential of medical plastic wastes. Waste Manag 2002;22:461-70. doi:10.1016/ S0956-053X(02)00006-5

37 USAID. AIDS support and technical assistance resources (AIDSTAR-One) project. Disposal of expired ARVs and test kits in Nigeria. PEPFAR. USAID, 2010. https://www.jsi.com/JSIInternet/Results/article/ display.cfm?txtGeoArea=INTL\&id=527\&thisSection= Results\&ctid=na\&cid=na\&tid $=20$

38 Miyazaki M, Imatoh T, Une H. The treatment of infectious waste arising from home health and medical care services: present situation in Japan. Waste Manag 2007;27:130-4. doi:10.1016/j. wasman.2005.12.018

39 American Academy of Family Physicians. Medical waste disposal in non-medical settings. 2003 https://www.aafp.org/about/policies/all/medicalwaste.html
40 Ripley K. Regional forum promotes 3Rs, resource efficiency to achieve multiple SDGs. SDG knowledge hub: a project by IISD, 2018. http://sdg.iisd.org/ news/regional-forum-promotes-3rs-resourceefficiency-to-achieve-multiple-sdgs/

41 World Health Organization. In: Chartier Y, Emmanuel J, Pieper U, et al, eds. Safe management of wastes from health-care activities. 2nd ed. 2014, http:// www.searo.who.int/srilanka/documents/safe management_of_wastes_from_healthcare_activities. pdf.

42 World Health Organization. Sustainable procurement of health-care commodities. WHO, 2018. http://www.who.int/sustainabledevelopment/health-sector/strategies/health-carecommodities/en/

43 Khan MS, Meghani A, Liverani M, Roychowdhury I, Parkhurst J. How do external donors influence national health policy processes? Experiences of domestic policy actors in Cambodia and Pakistan. Health Policy Plan 2018;33:215-23. doi:10.1093/ heapol/czx145

44 Chauhan A, Singh A. Healthcare waste management: a state-of-the-art literature review. Int J Environ Waste Manag 2016;18:120-44. doi:10.1504/ IJEWM.2016.080400

Cite this as: BM/ 2019;365:11298

http://dx.doi.org/10.1136/bmj..l1298 